\title{
Dose Responses of Years of Exposure on Lung Functions in Flour Mill Workers
}

\author{
Sultan A. Meo \\ Department of Physiology, College of Medicine, King Saud University Riyadh, K. S. A.
}

\begin{abstract}
Dose Responses of Years of Exposure on Lung Functions in Flour Mill Workers: Sultan A. Meo. Department of Physiology, College of Medicine, King Saud University Riyadh, K. S. A.Flour dust is a heterogeneous substance with respiratory sensitizing properties; its long-term exposure may cause acute or chronic respiratory diseases. Therefore, the aim was to investigate the dose response effects of flour dust on lung function. An additional objective was to minimize the potential health risks in flour mill workers by providing them with information about the hazards of flour dust. Pulmonary function was studied in forty-six male flour mill workers who worked without the benefit of flour dust control ventilation or respiratory protective devices and a similar number of male control subjects. All participants were non-smokers and were matched for age, height, weight and socio-economic status. Pulmonary function tests were performed by using an electronic Spirometer and results were compared by a paired $t$-test. The present study results showed a significant decrease in the mean values of FVC, FEV, PEF and MVV and this impairment was increased with duration of exposure in the flour mills. This group of flour mill workers had occupationally related pulmonary function impairment and stratification of results showed a dose response of years of exposure in flour mills on lung function. (J Occup Health 2004; 46: 187-191)
\end{abstract}

Key words: Occupational hazards, Flour dust, Pulmonary function test

The respiratory health effects have been documented in workers exposed to a variety of dusts in small and large-scale industries, which generate dust during their production process ${ }^{1)}$. The diseases of the respiratory system induced by occupational dusts are influenced by

Received June 30, 2003; Accepted Jan 21, 2004

Correspondence to: S. A. Meo, Department of Physiology (29), College of Medicine, King Saud University, P.O. Box 2925. Riyadh 11461.K.S.A. (e-mail: sultanmeo@hotmail.com) the type of dust and duration of exposure ${ }^{2)}$. Occupational diseases are caused by a pathologic response of the patients to their working environment ${ }^{3}$. Exposure to flour dust occurs across a range of food industries such as grain mills, flour mills and baking factories. The level of dust exposure is highest in the mixing and packing sites of the flour mills. Flour dust is a heterogeneous substance that may include particles from numerous cereal grains (wheat, barley, rye, oats, corn) and may contain a large number of contaminants including silica, fungi and their metabolites (aflatoxin), bacterial endotoxins, insects, mites, mammalian debris and various chemical additives such as pesticides and herbicides ${ }^{4}$.

Flour dust is a hazardous substance with respiratory sensitizing properties and may provoke asthma in individuals with pre-existing disease and also cause chronic bronchitis. In addition, flour and / or grain mill workers have been reported to exhibit a variety of clinical manifestations including allergic and bakers asthma, wheezing, febrile reactions, grain fever, lung fibrosis, rhinitis, conjunctivitis, allergic alveolitis, impairment of lung function and chronic obstructive pulmonary disease ${ }^{5 \text {. }}$.

In occupational respiratory disease, spirometry is one of the most important diagnostic tools. It is the most widely used, most basic, effort dependent pulmonary function test (PFT) and can measure the effects of restriction or obstruction on lung function ${ }^{6}$. Spirometry is regarded as an integral component of any respiratory medical surveillance program. During the preemployment evaluation, it can identify applicants with pre-existing respiratory impairments to ensure proper job placement and assist in the selection of appropriate respiratory protection. Periodic re-testing of workers can detect pulmonary disease in its earliest stages when corrective measures are more likely to be beneficial. Such intervention could include improvement in industrial hygiene control, job transfer or medical treatment. In addition, PFTs have assumed a key role in epidemiological studies investigating the incidence, natural history and causality of occupational and 
environmental respiratory disease ${ }^{7)}$. Keeping in view the hazards of flour dust, the present study was designed to investigate the dose response effect of flour dust on lung function. An additional objective was to reduce the potential health risks in flour mill workers by providing information about the hazards of flour dust.

\section{Material and Methods}

Subjects: Over several days, the author visited the Korangi Industrial zone, Karachi, Pakistan during the summer vacation July-August 2002 and interviewed approximately 80 flour mill workers. A detailed history was taken to determine whether they would be included in the study or not on the basis of the exclusion criteria. They were questioned with regard to smoking cigarettes, other tobacco products, chewing tobacco or betel nut products. After the initial interviews, 46 apparently healthy male flour mill workers with a mean age of 34.97 $\pm 1.90 \mathrm{yr}$ (mean \pm SEM), range $18-65 \mathrm{yr}$ with a mean duration of exposure of $6.30 \pm 0.39 \mathrm{yr}$ (mean \pm SEM), range $1-10 \mathrm{yr}$, were selected and 34 were excluded. These flour mill workers worked for at least $8-10 \mathrm{~h}$ a day for six days per week, without using any self-protective measures. Controls were selected in a similar manner to that of the flour mill workers, from approximately 90 interviewed, 46 apparently healthy male control subjects were selected with a mean age of $35.08 \pm 1.80 \mathrm{yr}$ (mean \pm SEM), range 20-60 yr. They were composed primarily of shopkeepers and salesmen. All subjects were matched for age, height, and weight with controls.

Exclusion criteria: Subjects with clinical abnormalities of the vertebral column, thoracic cage, neuromuscular diseases, known cases of gross anemia, diabetes mellitus, pulmonary tuberculosis, bronchial asthma, chronic bronchitis, bronchiectasis, emphysema, malignancy, drug addicts, cigarette smokers, tobacco chewers and subjects who had undergone vigorous exercise, abdominal or chest surgery and subjects having exposure to any industry other than flour mills were also excluded from the study.

\section{Methods}

Spirometry: Spirometry was performed on an electronic Spirometer (Compact Vitalograph UK). All pulmonary function tests were carried out at a fixed time of the day $(9.00-13.00 \mathrm{~h})$ to minimize any diurnal variation ${ }^{8)}$. The apparatus was calibrated daily and operated within the ambient temperature range of $20-25^{\circ} \mathrm{C}$. The precise techniques in executing various lung function tests for the present study were based on the operation manual of the instrument with special reference to the official statement of the American Thoracic Society of Standardization of Spirometry (1987) ${ }^{9)}$. After taking a detailed history and anthropometric data, the subjects were informed about the whole maneuver. The subjects were encouraged to practice this maneuver before doing the pulmonary function test. The test was performed with the subject in the standing position without using a nose clip. The test was repeated three times after adequate rest and the results obtained were available in the Spirometer. These parameters were Forced Vital Capacity (FVC), Forced Expiratory Volume in one second $\left(\mathrm{FEV}_{1}\right)$, Forced Expiratory Ratio (FEV $/$ FVC), Peak Expiratory Flow (PEF), Forced Expiratory Flow $\left(\mathrm{FEF}_{25-75 \%}\right)$ and Maximum Voluntary Ventilation (MVV).

Statistical Analysis: The statistical significance of difference between the mean values of the two groups was evaluated by students paired t-test. Statistical significance was noted if the $p$-value was less than 0.05 .

\section{Results}

The results are presented according to duration of exposure in the flour mills $(1-4,5-8$ and more than 8 yr). In Tables 1-3, the formal statistical comparison of the 'matching' variables (age, height and weight) was thought to be inappropriate, as these variables are inherently similar for the two groups and hence statistical confirmation of this fact is not discussed.

Duration of exposure 1-4 yr: Table 1 summarizes the comparison of the lung function parameters for flour mill workers and their matched control group. There was no significant difference in between the groups the means of any lung function data. The mean duration of exposure in flour mills was $3.09 \pm 0.31 \mathrm{yr}($ mean $\pm \mathrm{SEM})$, range 1 to $4 \mathrm{yr}$.

Duration of exposure 5-8 yr: Flour mill workers exposed for 5-8 yr, showed a significant reduction in FVC, FEV1, PEF and MVV compared with their matched controls (Table 2), but these workers did not show a significant reduction in $\mathrm{FEV}_{1} / \mathrm{FVC}$, and $\mathrm{FEF}_{25-75 \%}$ relative to controls. The percentage change in the flour mill workers data relative to controls was materially decreased for FVC, FEV1, PEF and MVV. The mean duration of exposure in flour mills was $6.18 \pm 0.24 \mathrm{yr}$ (mean \pm SEM), range 5 to $8 \mathrm{yr}$.

Duration of exposure for more than 8 yr: Flour mill workers exposed for longer than $8 \mathrm{yr}$, showed a significant reduction in FVC, FEV1, PEF and MVV relative to their matched controls (Table 3). Similarly, the percentage change in the flour mill workers data relative to controls was also significantly decreased for FVC, FEV1, PEF and $\mathrm{MVV}$, but there were no significant differences in $\mathrm{FEV}_{1} / \mathrm{FVC} \%$, and $\mathrm{FEF}_{25-75 \%}$ data relative to controls. The mean duration of exposure in this group was $9.23 \pm 0.12$ $\mathrm{yr}($ mean $\pm \mathrm{SEM})$, range 9-10 $\mathrm{yr}$.

\section{Discussion}

Flour dust contains particles from numerous cereal grains (wheat, barley, rye, oats, corn) and may contain a large number of contaminants including silica, fungi and their metabolites (aflatoxin), bacterial endotoxins, insects, 
Table 1. Anthropometric and lung function data for flour mill workers with duration of exposure for 1-4 yr, compared with their matched controls

\begin{tabular}{|c|c|c|c|c|}
\hline Parameter & $\begin{array}{l}\text { Flour mill workers } \\
(\text { mean } \pm \text { SEM })(n=11)\end{array}$ & $\begin{array}{c}\text { Control Subjects } \\
(\text { mean } \pm \text { SEM })(n=11)\end{array}$ & $\begin{array}{l}\text { Percentage } \\
\text { change }(\%)\end{array}$ & $p$ value \\
\hline Age (yr) & $23.18 \pm 2.64$ & $25.27 \pm 2.61$ & -8.27 & NS \\
\hline Height $(\mathrm{cm})$ & $171.00 \pm 1.74$ & $169.45 \pm 2.35$ & +0.91 & NS \\
\hline Weight $(\mathrm{kg})$ & $60.36 \pm 2.24$ & $63.27 \pm 2.76$ & -4.59 & NS \\
\hline FVC (litres) & $3.97 \pm 0.22$ & $4.45 \pm 0.20$ & -10.78 & NS \\
\hline $\mathrm{FEV}_{1}$ (litres) & $3.20 \pm 0.24$ & $3.51 \pm 0.21$ & -8.83 & NS \\
\hline $\mathrm{FEV}_{1} / \mathrm{FVC} \%$ & $80.36 \pm 4.19$ & $78.54 \pm 3.43$ & +2.31 & NS \\
\hline PEF (litres/min) & $316.39 \pm 54.36$ & $396.45 \pm 42.34$ & -20.19 & NS \\
\hline $\mathrm{FEF}_{25-75 \%}$ (litres/s) & $4.05 \pm 0.44$ & $4.19 \pm 0.51$ & -3.34 & NS \\
\hline MVV (litres/min) & $120.27 \pm 9.22$ & $131.72 \pm 8.14$ & -8.69 & NS \\
\hline
\end{tabular}

NS=non-significant

Table 2. Anthropometric and lung function data for flour mill workers with duration of exposure for 5-8 $\mathrm{yr}$ compared with their matched controls

\begin{tabular}{|c|c|c|c|c|}
\hline Parameter & $\begin{array}{c}\text { Flour mill workers } \\
(\text { mean } \pm \text { SEM) }(n=22)\end{array}$ & $\begin{array}{c}\text { Control Subjects } \\
(\text { mean } \pm \text { SEM })(n=22)\end{array}$ & $\begin{array}{l}\text { Percentage } \\
\text { change }(\%)\end{array}$ & $p$ value \\
\hline Age (yr) & $34.90 \pm 2.16$ & $35.04 \pm 2.18$ & -0.39 & NS \\
\hline Height $(\mathrm{cm})$ & $169.95 \pm 1.09$ & $169.09 \pm 1.28$ & +0.50 & NS \\
\hline Weight (kg) & $67.13 \pm 0.79$ & $66.77 \pm 1.51$ & +0.53 & NS \\
\hline FVC (litres) & $3.44 \pm 0.11$ & $4.46 \pm 0.18$ & -22.86 & $p<0.0005$ \\
\hline $\mathrm{FEV}_{1}$ (litres) & $2.73 \pm 0.15$ & $3.30 \pm 0.13$ & -17.27 & $p<0.0005$ \\
\hline $\mathrm{FEV}_{1} / \mathrm{FVC} \%$ & $78.54 \pm 3.24$ & $74.63 \pm 1.93$ & +5.23 & NS \\
\hline PEF (litres/min) & $293.95 \pm 28.79$ & $364.50 \pm 21.71$ & -19.35 & $p<0.02$ \\
\hline $\mathrm{FEF}_{25-75 \%}$ (litres/s) & $3.27 \pm 0.23$ & $3.51 \pm 0.24$ & -6.83 & NS \\
\hline MVV (litres/min) & $102.18 \pm 5.95$ & $124.13 \pm 4.92$ & -17.68 & $p<0.001$ \\
\hline
\end{tabular}

NS=non-significant

Table 3. Anthropometric and lung function data for flour mill workers with duration of exposure greater than 8 yr compared with their matched controls

\begin{tabular}{lcccc}
\hline Parameter & $\begin{array}{c}\text { Flour mill workers } \\
(\text { mean } \pm \text { SEM })(n=13)\end{array}$ & $\begin{array}{c}\text { Control Subjects } \\
(\text { mean } \pm \text { SEM })(n=13)\end{array}$ & $\begin{array}{c}\text { Percentage } \\
\text { change }(\%)\end{array}$ & $p$ value \\
\hline Age (yr) & $45.07 \pm 3.32$ & $43.46 \pm 3.40$ & +3.70 & NS \\
Height $(\mathrm{cm})$ & $166.84 \pm 0.95$ & $165.92 \pm 1.10$ & +0.55 & NS \\
Weight $(\mathrm{kg})$ & $65.30 \pm 1.12$ & $64.92 \pm 1.19$ & +0.58 & NS \\
FVC (litres) & $2.71 \pm 0.11$ & $3.96 \pm 0.12$ & -31.56 & $p<0.0005$ \\
FEV $_{1}$ (litres) & $1.88 \pm 0.14$ & $2.75 \pm 0.10$ & -31.63 & $p<0.0005$ \\
FEV $/$ FVC\% & $69.84 \pm 4.65$ & $69.53 \pm 1.94$ & +0.44 & NS \\
PEF (litres/min) & $185.61 \pm 20.14$ & $320.00 \pm 34.07$ & -41.99 & $p<0.006$ \\
FEF $25-75 \%(l i t r e s / s)$ & $2.25 \pm 0.32$ & $2.47 \pm 0.20$ & -8.90 & NS \\
MVV (litres/min) & $70.76 \pm 5.51$ & $103.23 \pm 3.84$ & -31.45 & $p<0.0005$ \\
\hline
\end{tabular}

NS=non-significant 
mites, mammalian debris and various chemical additives such as pesticides and herbicides. Workers exposed to flour dust during milling, transfer operations, mixing and baking processes may develop respiratory diseases ${ }^{10)}$. This study was designed to investigate the dose response of years of exposure to flour dust on lung function. The present study shows an association between pulmonary function impairment and duration of exposure to flour dust.

(Massin et al.,1995) ${ }^{11)}$ demonstrated the relation between dust exposure levels and the respiratory health status of workers in grain and flour mills and observed a dose-response relationship between dust exposure levels and chronic respiratory symptoms, suggesting that exposure to grain and flour dust may lead to chronic bronchitis. (Gimenez et al., 1995) ${ }^{12)}$ reported that, exposure to flour dust may induce chronic respiratory manifestations as well as lower pulmonary function values among mill workers by comparison with referents. In addition, Von Essen (1997) ${ }^{13)}$ demonstrated that grain dust exposure is a common cause of respiratory symptoms and these workers developed obstructive changes on pulmonary function testing. Similarly, we observed obstructive type changes on lung function testing in flour mill workers compared to their matched controls.

Corzo and Naveda (1998) ${ }^{14)}$ observed Spirometric changes due to high concentrations of wheat dust at a wheat processing plant in anthropometrically matched subjects. They reported a decrease in the Peak Flow Rate (PFR), Forced Expiratory Volume (FEV\%), Forced Expiratory Flow at 25\% $\left(\mathrm{FEF}_{25 \%}\right)$, and Forced Expiratory Flow at $75 \%\left(\mathrm{FEF}_{75 \%}\right)$. These Spirometric values diminished in a positive correlation with the time of exposure. Similarly, our results for PEF confirm the results observed by Corzo and Naveda $(1998)^{14)}$.

Awad et al., $(1986)^{15)}$ measured the lung function in workers exposed to flour dust and showed a significant drop in the forced expiratory volume in $1 \mathrm{~s}$ (FEV1.0) and forced vital capacity (FVC) in the exposed group. Ige and Awoyemi (2002) ${ }^{16)}$ reported that, the mean values of PEF, $\mathrm{FEV}_{1}, \mathrm{FVC}$ and FEV1\% in bakery workers were significantly lower than those of the control subjects. Similarly, Zodpey and Tiwari $(1998)^{17)}$ measured the Peak expiratory flow (PEFR) and reported that the PEFR was significantly reduced in flour mill workers as compared to their comparison group. The decline in PEFR was significantly associated with the duration of exposure. The present study results for $\mathrm{FVC}, \mathrm{FEV}_{1}$ and $\mathrm{PEF}$, confirm the results observed by Ige and Awoyemi (2002) ${ }^{16)}$ and Zodpey and Tiwari (1998) ${ }^{17)}$.

Post et al., (1998) ${ }^{18)}$ showed an annual decline in forced expiratory volume in one second (FEV1) and maximal mid-expiratory flow (MMEF), these parameters were significantly related to occupational exposure to dust in grain processing and in the animal feed industry. In addition, Bhat and Ramaswamy $(1991)^{19)}$ demonstrated that FVC, FEV1 and PEF were significantly reduced in rice mill workers compared to controls.

Yach et al., $(1985)^{10)}$ studied grain mill workers and found that the grain mill workers had significantly deteriorated lung function values compared to their matched controls. Chen, $(1992)^{20)}$ divided flour mill workers into a heavy-exposure group and light-exposure group and observed that FEV1, FVC, MMEF and PEF were significantly lower in heavy exposure than those in light exposures. The findings indicated that exposure to heavy concentrations of grain dust for a long period can impair pulmonary function.

In addition, Shamssain, $(1995)^{21)}$ observed the respiratory symptoms and ventilatory capacity in nonsmoking flour processing male bakery workers and reported that the exposed workers had significantly lower forced expiratory indices than the control group. Mean percent predicted values for forced expiratory volume in one second (FEV1), forced expiratory ratio (FEV1/FVC $\%$ ), forced mid-expiratory flow (FMF) between $25 \%$ and $75 \%$ of FVC, and peak expiratory flow rate (PEFR) were respectively, $11.2 \%, 20.0 \%, 31.0 \%$, and $36.1 \%$ lower in the exposed than in the controls.

Schwartz et al., (1995) ${ }^{22)}$ reported that grain mill workers had significantly reduced spirometric measures of airflow FEV1, FEV1/FVC, and FEF25-75. Zuskin et al., (1998) ${ }^{23)}$ found a significant across-shift reduction in ventilatory capacity in exposed workers, being the largest for flow rates at $50 \%$ and the last $25 \%$ of the vital capacity on maximum expiratory flow-volume (MEFV) curves (FEF50, FEF75). These data suggest that workers employed in the processing of flour may be at a risk for the development of respiratory impairment.

The present study confirms the findings of others and suggests that flour dust adversely affects lung function parameters, such as FVC, FEV1, PEF and MVV and causes an obstructive pattern of lung function impairment which is associated with the dose-effect of years of exposure to flour dust. The findings are of importance in that they demonstrate the extensive need for preventive measures and show the magnitude of the effect in a survivor population. It is advisable therefore, that flour mill managers, their workers and health officials should work together to adopt technical preventive measures, such as having well ventilated work areas and wearing appropriate respiratory protective devices. These measures will help to prevent lung damage, which often, over time, contributes to morbidity and mortality. It is also suggested that flour workers must undergo preemployment and periodic medical surveillance tests. These tests will identify susceptible workers, so that they can take adequate preventive measures as well as medication. 
Acknowledgments: I thank Dr. MM Feisal Subhan, Dr. Muhammad Mujahid Khan, Assistant professor, College of Medicine, King Saud University, for critical review of the manuscript. I am thankful to Mr. Bashir Ahmed and Imran Khan Meo (Medical student HCMD Karachi) for their help in the collection of data. I also extend my thanks to Mr. Ibraheem and Miss Nada A, Aziz A Salam, for typing the manuscript.

\section{References}

1) S Czeslawa, M Barbara, D Jacek, KT Ewa, M Janusz, F Helen, C Skorska, B Mackiewicz, J Dutkiewicz, E Krysinska-Traczyk, J Milanowski, H Feltovich, J Lange and P Thorne: Effects of exposure to grain dust in polish farmers: Work related symptoms and immunological response to microbial antigens associated with dust. Ann. Agric. Environ. Med 5, 147-153 (1998)

2) YA Mengesha and A Bekele: Relative chronic effects of occupational dusts on respiratory indices and health of workers in three Ethiopian factories. Am J Ind Med 34, 373-380 (1998)

3) Imbus, HR. Clinical aspects of occupational medicine. In: Occupational medicine. Edited by Carl, Zenz., O. Bruce. Dickerson, Edward, P. Horvath, JR, Third edition, Mosby, London, 1994: 3.

4) DJ Cotton and JA Dosman: Grain dust and health III. Environmental factors. Anal Int Med 89, 420-421 (1978)

5) JA Dosman, BL Graham and DJ Cotton: Chronic bronchitis and exposure to cereal grain dust. Am Rev Resp Dis 120, 477-480 (1979)

6) GL Ruppel: Pulmonary function testing. trends and techniques. Resp. Care. Clinics. North America 3, 155181 (1997)

7) McKay, Ray T. and Horvath Edward P. Pulmonary function testing in industry. In: Occupational medicine. Edited by Carl, Zenz., O, Bruce. Dickerson. Edward, P. Horvath. Third edition, Mosby, London, 1994: 229.

8) JW Glindmeyer, JJ Lefante, RN Jones, RJ Rando and $\mathrm{H}$ Weill: Cotton dust and across shift change in FEV as predictors of annual change in $\mathrm{FEV}_{1}$. Am J Resp Crit Care Med 149, 584-590 (1994)

9) American Thoracic Society. Statement on standardization of spirometry. Am Rev Res Dis 136, 1286-1296 (1987)

10) D Yach, J Myers, D Bradshaw and JE Merriman: A respiratory epidemiological survey of grain mill workers in Cape Town, South Africa. Am Rev Resp Dis 131, 505-510 (1985)

11) N Massin, AB Bohadana, P Wild, MN Kolopp-Sarda and JP Toamain: Airway responsiveness to methacholine, respiratory symptoms, and dust exposure levels in grain and flour mill workers in eastern France. Am J Ind Med 27, 859-869 (1995)

12) C Gimenez, K Fouad, D Choudat, J Laureillard, P Bouscaillou and E Leib: Chronic and acute respiratory effects among grain mill workers. Int Arch Occup Environ Health 67, 311-315 (1995)

13) S Von Essen: The role of endotoxin in grain dust exposure and airway obstruction. Curr Opin Pulm Med 3, 198-202 (1997)

14) G Corzo and R Naveda: Spirometry in workers in a wheat-processing industry. Invest Clin 1998; 39, 175187.

15) MA Awad el Karim, MO Gad el Rab, AA Omer and YA el Haimi: Respiratory and allergic disorders in workers exposed to grain and flour dusts. Arch Environ Health 41, 297-301 (1986)

16) OM Ige and OB Awoyemi: Respiratory symptoms and ventilatory function of the bakery workers in Ibadan, Nigeria. West Afr J Med 21, 316-318 (2002)

17) Zodpey SP, Tiwari RR. Peak expiratory flow rate in flour mill workers. Indian J Physiol Pharmacol, 1998; 42, 521-526.

18) W Post, D Heederik and R Houba: Decline in lung function related to exposure and selection processes among workers in the grain processing and animal feed industry. Occup Environ Med 55, 349-355 (1998)

19) MR Bhat and C Ramaswamy: A comparative study of lung functions in rice mill and saw mill workers. Indian J Physiol Pharmacol 35, 27-30 (1991)

20) Chen P: The effect of grain dust on non-specific bronchial hyperreactivity Zhonghua Jie $\mathrm{He}$ HeHuXiZaZhi, 1992, 15: 28-30, 62.

21) MH Shamssain: Respiratory symptoms and pulmonary function in flour processing workers in the baking industry. Am J Ind Med 27, 359-365 (1995)

22) DA Schwartz, PS Thorne, SJ Yagla, LF Burmeister, SA Olenchock, JL Watt and TJ Quinn: The role of endotoxin in grain dust-induced lung disease. Am J Resp. Crit Care Med 152, 603-608 (1995)

23) E Zuskin, B Kanceljak, EN Schachter, J Godnic-Cvar, J Mustajbegovic and A Budak: Respiratory function and immunological status in cocoa and flour processing workers. Am J Ind Med 33, 24-32 (1998) 